\title{
Analisis Kinerja Sistem Penggilingan Gabah Sebagai Penunjang Usaha Pertanian Berkelanjutan (Studi Kasus di Kecamatan Penebel, Kabupaten Tabanan)
}

\section{Analysis of Grain Milling System Performance as a Support for Sustainable Agriculture Business (Case Study in Penebel Subdistrict, Tabanan Regency)}

\author{
Ni Made Ayu Manik Suantari, I G.N. Apriadi Aviantara, I. A. Rina Pratiwi Pudja \\ Program Studi Teknik Pertanian, Fakultas Teknologi Pertanian Unud \\ E-mail: yumanik28@gmail.com
}

\begin{abstract}
Abstrak
Tujuan dari penelitian ini adalah untuk mengetahui kondisi kinerja mesin dari penggilingan gabah dan mengetahui berapa persen kapasitas yang terpakai dalam penggilingan gabah sehingga dapat mengukur dan menilai keberlanjutan dari produktivitas finansial pada usaha penggilingan gabah. Analisis keberlanjutan finansial menggunakan analisis menghitung NPV (Net Present Value), IRR (Internal Rate of Return), dan BCR (Benefit Cost Ratio). NPV (Net Present Value) adalah salah satu kriteria terpenting dalam evaluasi sebuah investasi, menunjukkan bahwa selisih jumlah kas yang dihasilkan proyek investasi dan nilai investasi yang diperlukan. IRR (Internal Rate of Return) adalah suatu investasi dapat dilakukan apabila laju pengembaliannya lebih besar daripada laju pengembalian investasi ditempat lain. BCR (Benefit Cost Ratio) merupakan suatu analisis yang diperlukan untuk melihat sudah sampai sejauh mana perbandingan antara nilai manfaat terhadap nilai biaya jika dilihat pada kondisi nilai saat ini PV (Present Value). Berdasarkan pada tabel Analisis kinerja operasional produktivitas didapatkan kontribusi terhadap kinerja pada PGK yaitu 21,1\%, PGM 32.3\% dan PGB 47,5\%. Sehingga dalam penggilingan gabah berdasarkan hasil sampling rata-rata yang ada di Kecamatan Penebel untuk PGB mempunyai kontribusi terhadap kinerja operasional yang paling besar dan pada tabel kondisi kinerja mesin penggilingan gabah dalam Intensitas Operasi yang dikerjakan dimana pelaku usaha penggilingan gabah yaitu penggilingan kapasitas besar, menengah ini memiliki kegiatan investasi yang bisa dikatakan layak untuk dilanjutkan atau dikembangkan kembali namun tidak dengan kapasitas kecil karena penggilingan tersebut dikatakan tidak layak untuk dilanjutkan. Hal ini didasarkan pada hasil sampling rata-rata pada setiap kapasitas penggilingan gabah yang terpasang dengan analisis kelayakan finansial yaitu NPV (Net Present Value) yang setiap kapasitasnya berbeda yaitu kapasitas besar Rp. 306.400.273, kapasitas menengah Rp. 190.596 .835 dan kapasitas kecil Rp. 15.890.115. IRR (Internal Rate of Return) kapasitas besar 48\%, kapasitas menengah $24 \%$ dan kapasitas kecil 0.6\%. B/C Ratio (Benefit Cost Ratio) kapasitas besar mendapatkan 2,18 dan kapasitas menengah mendapatkan 1,75 sedangkan kapasitas kecil hanya 1,0.
\end{abstract}

Kata kunci: Gabah, usaha penggilingan gabah, keberlanjutan finansial.

\begin{abstract}
The purpose of this study are to know the condition og grain milling machine performance and to know the percentage of capacity used in the machine, thus can measure and assess the sustainability of the financial productivity of the grain milling business. Financial sustainability analyzes use NPV (Net Present Value), IRR (Internal Rate of Return), and BCR (Benefit Cost Ratio) calculations. NPV (Net Present Value) is one of the most important criteria in the evaluation of an investment, indicating that the difference in the amount of cash generated by the investment project and the value of the investment required. IRR (Internal Rate of Return) is an investment can be done if the rate of return is greater than the rate of return on investment at another place. BCR (Benefit Cost Ratio) is an analysis required to see how far the comparison between the value of benefits to the value of the cost when viewed at the current value of PV (Present Value). Based on the table of operational performance of productivity analysis, contribution to performance on small
\end{abstract}


capacity is $21,1 \%$, medium capacity is $32.3 \%$, and large capacity is $47,5 \%$. Therefore, based on the average sampling results in Penebel Sub-district, grain milling with large capacity has the greatest contribution to operational performance and on the table of grinding machine performance conditions in the Operation Intensity done where the grain milling business actors namely the milling of large, medium, capacity has investment activities that can be said worthy to be continued or developed again but not with a small capacity because the milling is said to be inappropriate to continu. Based on the average sampling result on each grain milling capacity installed with a financial feasibility analysis of NPV (Net Present Value) has different capacity where large capacity is Rp. 306.400.273, medium capacity is Rp. 190.596.835, and small capacity is Rp. 15.890.115. In IRR (Internal Rate of Return) large capacity is $48 \%$, medium capacity is $24 \%$, and small capacity is $0,6 \%$. In B / C Ratio (Benefit Cost Ratio), large capacity is 2.18 , medium capacity is 1.75 , meanwhile small capacity is 1,0 .

Keyword: Grain, Grain Milling Business, Agricultural Business, Financial Sustainability

\section{PENDAHULUAN}

Sistem penggilingan padi merupakan rangkaian mesin yang berfungsi untuk melakukan proses giling gabah, yaitu dari bentuk gabah kering giling sampai menjadi beras siap konsumsi. Melalui penggilingan, gabah memiliki nilai tambah sebesar 400-600\% dalam bentuk beras giling (Rachmat et al. dalam Thahir 2010). Selain itu, penggilingan padi merupakan pusat pertemuan antara produksi, pascapanen, pengolahan, dan pemasaran gabah. Penggilingan padi memiliki peran yang sangat penting dalam sistem agribisnis padi atau perberasan di Indonesia. Hal ini menyebabkan penggilingan padi sebagai mata rantai penting dalam suplai beras nasional yang dituntut dapat memberikan kontribusi dalam penyediaan beras, baik dari segi kuantitas maupun kualitas untuk mendukung ketahanan pangan nasional.

Pertanian berkelanjutan adalah sebagai sebuah sistem terintegrasi antara praktik produksi tanaman dalam sebuah lokasi dan dalam jangka panjang memiliki fungsi sebagai berikut: Memenuhi kebutuhan pangan dan serat manusia, meningkatkan kualitas lingkungan dan sumber daya alam berdasarkan kebutuhan ekonomi pertanian, menggunakan sumber daya alam tidak terbarukan secara efisien, menggunakan sumber daya yang tersedia di lahan pertanian secara terintegrasi, jika memungkinkan, meningkatkan kualitas hidup petani dan masyarakat secara keseluruhan.Tahapan menuju pertanian berkelanjutan seringkali dipandang sebagai sebuah tahapan dan bukan sebagai akhir. Beberapa menganggap bahwa pertanian berkelanjutan yang sebenarnya adalah yang berkelanjutan secara ekonomi. (Sa'id, et al. 2002). Maka perlu dilakukan analisis kinerja secara spesifik yang baik dalam finansial dan produksi dari penggilingan gabah agar dalam usaha penggilingan gabah kita dapat mengetahui apakah usaha penggilingan gabah tersebut dapat berlanjut atau tidak untuk dijalankan. Berdasarkan hal tersebut maka dilakukan penelitian mengenai Analisis Kinerja Sistem Penggilingan Gabah Sebagai Penunjang Usaha Pertanian Berkelanjutan (Studi Kasus di Kecamatan Penebel, Kabupaten Tabanan). Penelitian ini bertujuan untuk mengetahui berapa persen kapasitas yang terpakai dalam penggilingan gabah dan mengetahui kondisi kinerja mesin dari penggilingan gabah untuk dapat mengukur dan menilai keberlanjutan dari produktivitas finansial ekonomi pada usaha penggilingan gabah di Kecamatan Penebel, Kabupaten Tabanan. Penelitian ini dilakukan dengan penyebaran kuisioner kepada pelaku usaha penggilingan gabah berdasarkan dengan kapasitas mesin yang terpasang yaitu penggilingan gabah dengan kapasitas mesin besar, menengah dan kecil untuk mengetahui jumlah produksi gabah yang akan digilling dengan kapasitas yang berbeda serta kinerja pada mesin penggilingan gabah sehingga dapat melihat suatu usaha keberlanjutan dari penggilingan gabah di Kecamatan Penebel,Kabupaten Tabanan.

\section{METODE PENELITIAN}

\section{Lokasi dan Waktu Kegiatan}

Penelitian ini dilakukan di Kecamatan Penebel

Kabupaten Tabanan mencakup RMU dengan beberapa kriteria kapasitas penggilingan yaitu penggilingan gabah kecil, penggilingan gabah menengah dan penggilingan gabah besar yang terdapat didalam Kecamatan Penebel. Penentuan daerah penelitian ditentukan secara purposive dengan pertimbangan bahwa lokasi penelitian merupakan daerah yang cukup banyak terdapat penggilingan gabah dan merupakan salah satu sentra produksi gabah untuk Provinsi Bali. Waktu penelitian ini dilakukan dari bulan Oktober sampai Desember 2017. 


\section{Populasi dan Sampel Penelitian}

Dalam penelitian ini, metode yang digunakan adalah Purposive Sampling. Dalam hal ini pemilihan responden dipilih secara sengaja. Populasi merupakan generalisasi yang terdiri dari objek atau subjek yang memiliki kualitas dan karakteristik khusus yang telah ditetapkan untuk diteliti, dipelajari dan ditarik kesimpulannya (Sugiyono, 2012). Responden penelitian diantaranya pelaku usaha penggilingan gabah, dan lembaga swadaya masyarakat.

\section{Pelaksanaan Penelitian}

Kuisioner merupakan salah satu teknik pengumpulan data dengan memberikan sejumlah pertanyaan atau pernyataan tertulis kepada responden untuk dijawabnya (Sugiyono, 2012). Instrumen pengumpulan data dalam penelitian ini berupa kuisioner atau angket yang disusun berdasarkan komponen-komponen yang diperlukan dalam analisis data. Metode pengumpulan data dalam penelitian ini adalah wawancara secara langsung ke pelaku usaha penggilingan gabah dengan hasil sampling yang didapat 33 penggilingan gabah di Kecamatan Penebel.

\section{Analisis Data}

Data yang digunakan berupa data primer dan data sekunder. Data primer dilakukan dengan survey langsung ke lokasi dan wawancara terstruktur (menggunakan kuesioner) kepada para responden yakni pemilik penggilingan gabah di Kecamatan Penebel di setiap Desa yang jumlahnya masingmasing telah ditentukan menggunakan Metode Purposive Sampling. Besaran sampel yang digunakan dalam studi adalah $30 \%$ dari populasi penggilingan gabah di kecamatan penebel, Kabupaten Tabanan sesuai dengan standar statistik bahwa jumlah sampel minimum adalah lebih besar dari atau sama dengan $30(n>30)$. Data sekunder diperoleh melalui pengumpulan data terkait dengan penggilingan gabah didaerah Penebel Kabupaten Tabanan berupa data laporan tahunan instansi terkait dan data terkait lainnya.Analisis data dalam penelitian ini menggunakan analisis deskriptif kuantitatif melalui pendekatan konsep manajemen. Analisis kuantitatif menggunakan perhitungan NPV (Net Present Value), IRR (Internal Rate of Return), dan BCR (Benefit Cost Ratio).

\section{HASIL DAN PEMBAHASAN}

\section{Gambaran Umum Penggilingan Gabah}

Kabupaten Tabanan khususnya Kecamatan Penebel sudah sejak lama dikenal sebagai salah satu daerah penghasil padi dan sekaligus sebagai produsen beras terbesar di Bali. Dengan lahan sawahnya yang luas dan subur serta didukung iklim yang optimal, dalam hal produksi padi Kecamatan Penebel selalu menempati posisi tertinggi. Hal inilah yang menguatkan predikat Kecamatan Penebel sebagai "lumbung berasnya Bali" di Kabupaten Tabanan, karena sebagaian besar produksi padi yang dihasilkan diolah masyarakat setempat. Sejak teknologi penggilingan gabah ini mulai diperkenalkan di Indonesia, masyarakat didaerah ini telah aktif menggembangkan unit usaha penggilingan padi baik dalam skala kecil, menengah maupun skala besar yang terbesar di seluruh desa yang ada. Sampai pada tahun 2016, tercatat jumlah unit penggilingan gabah yang ada di Kecamatan Penebel Kabupaten Tabanan sebanyak 114 unit usaha, dan sebagai besar merupakan unit Penggilingan Padi Kecil (PPK) dengan konfigurasi proses penggilingan yang beragam. Hasil dari penggilingan padi yang berupa beras tersebut pun langsung dijual perkilogramnya oleh pelaku usaha penggilingan gabah di Kecamatan Penebel guna untuk meningkatkan finansial mereka sendiri, terkadang mereka juga memberikan jasa gilling kepada para petani.

\section{Analisis Kinerja Operasional Produktivitas Industri RMU di Kecamatan Penebel}

Untuk membuktikan bahwa industri RMU di Kecamatan Penebel Kabupaten Tabanan beroperasi dibawah kapasitas yang terpasang, dimana didalam penelitian ini diambil sebanyak 30\% dari populasi industri (114 unit) untuk mengetahui kinerja operasional produktivitas penggilingan gabah dalam kapasitas besar, kapasitas menengah dan kapasitas kecil.dapat dilihat pada Tabel 1.

Tabel 1. Analisis Kinerja Operasional Produktivitas RMU

\begin{tabular}{llcccc}
\hline \multirow{2}{*}{ No } & \multicolumn{1}{c}{ Indikator Kinerja } & \multicolumn{3}{c}{ Kategori Industri RMU } & \multirow{2}{*}{ RATA-RATA } \\
& & PPK & PPM & PPB & \\
\hline 1 & Jumlah Populasi RMU berdasarkan sampling & 27 & 4 & 3 & 33 \\
2 & Kapasitas Giling perjam & 0,4 ton & 0,8 ton & 1,6 ton & \\
3 & Volume Giling perhari & 1,12 ton & 1 ton & 1,60 ton & \\
4 & Intensitas Operasi perbulan (hari) & 9,0 kali & 20 kali & 25 kali & \\
5 & Volume Giling perbulan & 10 ton & 20 ton & 40 ton & \\
6 & Volume Giling dalam setahun & 120 ton & 240 ton & 480 ton & \multirow{2}{*}{840 ton } \\
7 & Kontribusi terhadap kinerja & $21,1 \%$ & $32,3 \%$ & $47,5 \%$ & $100 \%$ \\
\hline
\end{tabular}

Sumber : Data Primer Diolah 2018

Data pada Tabel 1 menunjukan bahwa operasional produktivitas penggilingan gabah dalam setiap kapasitasnya dari hasil sampling di Kecamatan Penebel rata-rata mampu menggiling gabah sebanyak 840 ton dalam setahun. Dari jumlah tersebut dapat ditentukan berapa persen kapasitas yang terpakai dalam penggilingan gabah pada setiap kapasitasnya juga dapat menentukan peroduktivitas dalam setahun 
di Kecamatan Penebel Kabupaten Tabanan dimana didapatkan kontribusi terhadap kinerja PGK yaitu 21,1\%, kontribusi terhadap kinerja PGM yaitu $32.3 \%$ dan kontribusi terhadap kinerja PGB yaitu $47,5 \%$. Sehingga dalam penggilingan gabah yang ada di Kecamatan Penebel untuk PPB mempunyai kontribusi terhadap kinerja operasional yang paling besar.

\section{Analisis Net Present Value (NPV)}

Untuk menghitung NPV diperlukan data tentang perkiraan biaya investasi, biaya operasi, dan pemeliharaan serta perkiraan manfaat atau benefit dari proyek yang direncanakan. Arus kas masuk dan keluar yang didiskonkan pada saat ini (present value (PV)) yang dijumlahkan selama masa hidup dari proyek tersebut. Dimana dalam kurun waktu 5 tahun telah diperolehkan hasil pada Tabel 2, Tabel 3 dan Tabel 4.

Tabel 2. Hasil Analisis Net Present Value (NPV) Penggilingan Gabah Kapasitas Besar

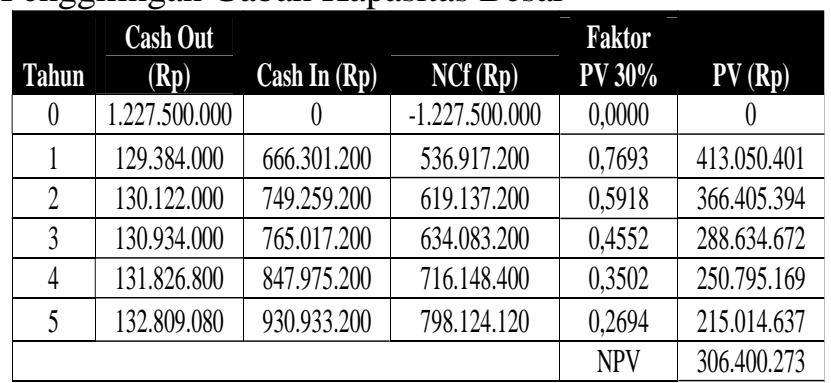

Sumber: Data Primer Diolah 2018

Tabel 3. Hasil Analisis Net Present Value (NPV) Penggilingan Gabah Kapasitas Menengah

\begin{tabular}{|c|c|c|c|c|c|}
\hline Tahun & $\begin{array}{c}\text { Cash Out } \\
\text { (Rp) }\end{array}$ & $\begin{array}{c}\text { Cash In } \\
\text { (Rp) }\end{array}$ & $\mathrm{NCf}(\mathbf{R p})$ & $\begin{array}{l}\text { Faktor } \\
\text { PV 15\% }\end{array}$ & PV (Rp) \\
\hline 0 & 328.750 .000 & 0 & -328.750 .000 & 0,0000 & 0 \\
\hline 1 & 63.292 .000 & 187.659 .000 & 124.367 .000 & 0,8696 & 108.149 .543 \\
\hline 2 & 63.916 .000 & 212.179 .000 & 148.263 .000 & 0,7562 & 112.116 .481 \\
\hline 3 & 64.600 .800 & 216.299.000 & 151.698 .000 & 0,6576 & 99.755 .604 \\
\hline 4 & 65.354 .880 & 240.819 .000 & 175.464 .120 & 0,5718 & 100.330 .384 \\
\hline \multirow[t]{2}{*}{5} & 66.184 .368 & 265.289 .000 & 199.104.632 & 0,4972 & 98.994 .823 \\
\hline & & & & NPV & 190.596 .835 \\
\hline
\end{tabular}

Sumber : Data Primer Diolah 2018

Tabel 4. Hasil Analisis Net Present Value (NPV) Penggilingan Gabah Kapasitas Kecil

\begin{tabular}{cccccc} 
Tahun & $\begin{array}{c}\text { Casil Uul } \\
(\mathbf{R p})\end{array}$ & $\begin{array}{c}\text { Casil II } \\
(\mathbf{R p})\end{array}$ & $\mathbf{N C f}(\mathbf{R p})$ & $\begin{array}{c}\text { Fakcor } \mathbf{~} \mathbf{1 0} \\
\text { PV }\end{array}$ & $\mathbf{P V})$ \\
\hline 0 & 27.037 .036 & 0 & -27.037 .036 & 0,0000 & 0 \\
1 & 23.909 .324 & 26.112 .409 & 2.203 .085 & 0,9091 & 2.002 .824 \\
2 & 24.319 .324 & 27.458 .409 & 3.139 .085 & 0,8264 & 2.594 .139 \\
3 & 24.770 .324 & 27.191 .609 & 2.412 .285 & 0,7513 & 1.812 .349 \\
4 & 25.266 .424 & 28.501 .609 & 3.235 .185 & 0,6830 & 2.209 .631 \\
5 & 25.812 .134 & 29.083 .609 & 4.071 .475 & 0,6209 & 2.527 .978 \\
\hline
\end{tabular}

Sumber : Data Primer Diolah 2018
Dari hasil perhitungan pada Tabel 2, Tabel 3 dan Tabel 4 telah diperoleh NPV pada penggilingan gabah kapasitas besar dan menengah bernilai positif $>0$ sedangkan penggilingan gabah pada kapasitas kecil bernilai negatif $<0$, dimana telah didapatkan hasil analisis NPV yaitu penggilingan gabah kapasitas besar Rp. 306.400.273 dimana nilai tersebut menunjukkan bahwa investasi yang ditanam selama 5 tahun mendatang akan memperoleh pengembalian modal dan keuntungan bersih, penggilingan gabah kapasitas menengah yaitu $\mathrm{Rp}$. 190.596.835 dimana dapat dikatakan juga nilai tersebut menunjukkan bahwa investasi yang ditanam selama 5 tahun mendatang akan memperoleh pengembalian modal dan keuntungan bersih untuk penggilingan gabah kapasitas kecil yaitu Rp. 15.890.115 dimana dapat dikatakan jika hasil tersebut tidak dapat mengalami pengembalian modal selama 5 tahun mendatang namun mengalami kerugian sehingga tidak memperoleh keuntungan bersih yang diinginkan.

\section{Analisis Internal Rate of Return (IRR)}

Metode Internal Rate of Return digunakan untuk mencari tingkat bunga yang menyamakan nilai sekarang dari arus kas yang diharapkan di masa datang, atau penerimaan kas dengan mengeluarkan investasi awal (Umar, 2000). Perhitungan secara manual mencari nilai Internal Rate of Return (IRR). Dengan menggunakan tingkat suku bunga MARR $20 \%$ telah diperoleh hasil pada Tabel 5, Tabel 6 dan Tabel 7.

Tabel 5. Hasil Analisis Internal Rate of Return (IRR) Penggilingan Gabah Kapasitas Besar

\begin{tabular}{|c|c|c|c|c|}
\hline \multirow{2}{*}{ Tahun } & \multirow[b]{2}{*}{$\begin{array}{l}\text { Cash Out } \\
\text { (Rp) }\end{array}$} & \multirow[b]{2}{*}{$\begin{array}{c}\text { Cash In } \\
\text { (Rp) }\end{array}$} & \multirow{2}{*}{ NCf (Rp) } & \multirow{2}{*}{$\begin{array}{l}\text { Discounting Cash } \\
\text { Flow }\end{array}$} \\
\hline & & & & \\
\hline 0 & 1.227 .500 .000 & 0 & -1.227 .500 .000 & -1.227 .500 .000 \\
\hline 1 & 129.384 .000 & 666.301 .200 & 536.917 .200 & 413.050 .401 \\
\hline 2 & 130.122 .000 & 749.259 .200 & 619.137 .200 & 366.405 .394 \\
\hline 3 & 130.934 .000 & 765.017 .200 & 634.083 .200 & 288.634 .672 \\
\hline 4 & 131.826 .800 & 847.975 .200 & 716.148 .400 & 250.795 .169 \\
\hline \multirow[t]{3}{*}{5} & 132.809 .080 & 930.933 .200 & 798.124.120 & 215.014 .637 \\
\hline & & & Total & 306.400 .273 \\
\hline & & & IRR & $48 \%$ \\
\hline
\end{tabular}

Sumber : Data Primer Diolah 2018

Tabel 6. Hasil Analisis Internal Rate of Return (IRR) Penggilingan Gabah Kapasitas Menengah 


\begin{tabular}{|c|c|c|c|c|}
\hline & & & & \multicolumn{2}{c|}{$\begin{array}{l}\text { Discounting Cash } \\
\text { Flow }\end{array}$} \\
\cline { 5 - 5 } Tahun & $\begin{array}{c}\text { Cash Out } \\
\mathbf{( R p )}\end{array}$ & Cash In (Rp) & NCf $(\mathbf{R p})$ & $\mathbf{1 5 \%}$ \\
\hline 0 & 328.750 .000 & 0 & -328.750 .000 & -328.750 .000 \\
1 & 63.292 .000 & 187.659 .000 & 124.367 .000 & 108.149 .543 \\
2 & 63.916 .000 & 212.179 .000 & 148.263 .000 & 112.116 .481 \\
3 & 64.600 .800 & 216.299 .000 & 151.698 .000 & 99.775 .604 \\
4 & 65.354 .880 & 240.819 .000 & 175.464 .120 & 100.330 .384 \\
5 & 66.184 .368 & 265.289 .000 & 199.104 .632 & 98.994 .823 \\
\hline & & & Total & 190.529 .835 \\
\cline { 4 - 5 } & & & IRR & $24 \%$ \\
\hline
\end{tabular}

Tabel 7. Hasil Analisis Internal Rate of Return (IRR) Penggilingan Gabah Kapasitas Kecil

\begin{tabular}{|c|c|c|c|c|}
\hline Tahun & $\begin{array}{c}\text { Cash 0ut } \\
\text { (Rp) }\end{array}$ & Cash In (Rp) & $\mathrm{NCf}(\mathbf{R p})$ & $\begin{array}{l}\text { Disconting Cash } \\
\text { Flow } \\
\\
10 \%\end{array}$ \\
\hline 0 & 27.037 .036 & 0 & -27.037 .036 & -27.037 .036 \\
\hline 1 & 23.909 .324 & 26.112 .409 & 2.203 .085 & 2.002 .824 \\
\hline 2 & 24.790 .324 & 27.458 .409 & 3.139 .085 & 2.594 .139 \\
\hline 3 & 24.770 .324 & 27.191 .609 & 2.412 .285 & 1.812 .349 \\
\hline 4 & 25.266 .424 & 28.501 .609 & 3.235 .185 & 2.209 .631 \\
\hline \multirow[t]{3}{*}{5} & 25.812.134 & 29.883 .609 & 4.071 .475 & 2.527 .978 \\
\hline & & & Total & -15.890 .978 \\
\hline & & & IRR & $0,6 \%$ \\
\hline
\end{tabular}

Sumber : Data Primer Diolah 2018

Dari hasil perhitungan pada Tabel 5, Tabel 6 dan Tabel 7 telah diperoleh nilai IRR dalam penggilingan gabah kapasitas besar dan menengah bernilai positif $>$ MARR 20\%, sedangkan penggilingan gabah kapasitas kecil bernilai negatif < MARR 20\% dimana telah didapatkan hasil analisis IRR yaitu penggilingan gabah kapasitas besar dengan kapasitas besar $48 \%$, penggilingan gabah kapasitas menengah $24 \%$ dan penggilingan gabah kapasitas kecil 0,6\% yang artinya usaha penggilingan gabah kapasitas besar dan menengah dapat mengembalikan modal hingga tingkat bunga pinjaman yang dihasilkan sedangkan penggilingan kapasitas kecil tidak mampu untuk mengembalikan modal hingga tingkat bunga pinjaman.

\section{Analisis Benefit Cost Ratio (BCR)}

Analisis Benefit Cost Ratio (BCR) merupakan suatu analisis yang diperlukan untuk melihat sudah sampai sejauh mana perbandingan antara nilai manfaat terhadap nilai biaya jika dilihat pada kondisi nilai saat ini/ Present Value (PV). Perhitungan nilai BCR akan dilakukan dengan cara melihat tingkat suku bunga yang sedang terjadi, dimana jika nilai BCR pada suku bunga yang berlaku > 1, maka proyek atau suatu usaha dikatakan dapat dilanjutkan secara ekonomi dan bisa dikatakan untuk dimulai(Umar,2000). Hasil dari analisis Benefit Cost Ratio (BCR) telah diperoleh pada Tabel 8, Tabel 9 dan Tabel 10.

Tabel 8. Hasil Analisis Benefit Cost Ratio (BCR) Penggilingan Gabah Kapasitas Besar

\section{Uraian}
Nilai Investasi
Rp. 1.227.500.000
Laba Bersih
Rp. 653.797 .200
Hasil Samping
Rp. 19.200 .000
Benefit pertahun
Rp. 672.997 .200
Rate
$15 \%$
Nilai Residu
$10 \%$
Penyusutan Mesin
5 tahun

Biaya Operasional

Total Biaya

Rp. 122.004 .000

B/C Ratio

Rp. 308.379 .720

Sumber : Data Primer Diolah 2018

Tabel 9. Hasil Analisis Benefit Cost Ratio (BCR) Penggilingan Gabah Kapasitas Menengah

\begin{tabular}{lc}
\multicolumn{1}{c}{ Uraian } & Jumlah \\
Nilai Investasi & Rp. 328.750 .000 \\
Laba Bersih & Rp. 175.899 .000 \\
Hasil Samping & Rp. 14.400 .000 \\
Benefit pertahun & Rp. 190.299 .000 \\
Rate & $15 \%$ \\
Nilai Residu & $10 \%$ \\
Penyusutan Mesin & 5 tahun \\
Biaya Operasional & Rp. 57.060 .000 \\
Total Biaya & Rp. 108.489 .300 \\
\hline B/C Ratio & 1,75 \\
\hline
\end{tabular}

Sumber : Data Primer Diolah 2018

Tabel 10. Hasil Analisis Benefit Cost Ratio (BCR) Penggilingan Gabah Kapasitas Kecil

\begin{tabular}{lc}
\multicolumn{1}{c}{ Uraian } & Jumlah \\
Nilai Investasi & Rp. 27.037 .036 \\
Laba Bersih Tahun 1 & Rp. 18.072 .409 \\
Hasil Samping & Rp. 9.600 .000 \\
Benefit pertahun & Rp. 27.672 .608 \\
Rate & $15 \%$ \\
Nilai Residu & $10 \%$ \\
Penyusutan Mesin & 5 tahun \\
Biaya Operasional & Rp. 19.809 .324 \\
Total Biaya & Rp. 25.312 .079 \\
\hline B/C Ratio & 1,0 \\
\hline
\end{tabular}

Sumber : Data Primer Diolah 2018

Dari hasil perhitungan pada Tabel 8, Tabel 9 dan Tabel 10 telah diperoleh nilai $B / C$ Ratio dalam penggilingan gabah kapasitas besar dan menengah bernilai positif $>1$ sedangkan penggilingan gabah kapasitas kecil bernilai negatif $<1$ dimana telah didapatkan hasil analisis BCR yaitu penggilingan gabah kapasitas besar 2,18, penggilingan gabah kapasitas menengah 1,75 dan penggilingan gabah kapasitas kecil 1,0 yang artinya usaha penggilingan 
gabah pada kapasitas besar dan menengah memiliki kegiatan investasi yang bisa dikatakan layak untuk dilanjutkan sedangkan kapasitas kecil memiliki kegiatan investasi yang tidak dapat dikatakan layak untuk.

\section{Kondisi Kinerja Mesin Penggilingan Gabah untuk Keberlanjutan Usaha Pertanian di Kecamatan Penebel \\ Penggilingan Gabah dalam setiap kapasitasnya di Kecamatan Penebel Kabupaten Tabanan dapat kita lihat kondisi kinerja mesinnya dalam penunjang usaha pertanian berkelanjutan yang dihitung dalam analisis finansial Net Present Value (NPV), Internal Rate of Return (IRR) dan Benefit Cost Ratio (BCR) pada Tabel 11.}

Tabel 11. Kondisi Kinerja Mesin Penggilingan Gabah

\begin{tabular}{|c|c|c|c|c|}
\hline \multirow[t]{2}{*}{ No } & \multirow[t]{2}{*}{ Indikator Kinerja } & \multicolumn{3}{|c|}{ Kategori Industri RMU } \\
\hline & & PGK & PGM & PGB \\
\hline 1 & Rata- rata kapasitas giling & 0,4 ton/jam & 0,8 ton/jam & 1,6 ton/jam \\
\hline 2 & $\begin{array}{l}\text { Volume penggilingan } \\
\text { perbulan }\end{array}$ & 10 ton & 20 ton & 40 ton \\
\hline 3 & $\begin{array}{l}\text { Intensitas operasi perbulan } \\
\text { (hari) }\end{array}$ & 9,0 kali & 20 kali & 25 kali \\
\hline 4 & $\begin{array}{l}\text { Harga pembelian bahan } \\
\text { baku }\end{array}$ & $\begin{array}{l}\text { Rp. } 4.900- \\
5.000 / \mathrm{kg}\end{array}$ & $\begin{array}{l}\text { Rp. } 4.900- \\
5.000 / \mathrm{kg}\end{array}$ & $\begin{array}{l}\text { Rp. } 4.900- \\
5.000 / \mathrm{kg}\end{array}$ \\
\hline 5 & Harga penjualan beras & Rp. $9.400 / \mathrm{kg}$ & Rp. $9.400 / \mathrm{kg}$ & Rp. $9.400 / \mathrm{kg}$ \\
\hline 6 & $\begin{array}{l}\text { Analisis finansial } \\
\text { NPV,IRR dan B/C Ratio }\end{array}$ & $\begin{array}{l}\text { NPV }= \\
\text { Rp. }-15.890 .115 \\
\text { IRR }=0,6 \% \\
\text { B/C Ratio = } 1\end{array}$ & $\begin{array}{l}\text { NPV }= \\
\text { Rp. } 190.596 .835 \\
I R R=24 \% \\
\text { B/C Ratio }=1,75\end{array}$ & $\begin{array}{l}\text { NPV }= \\
\text { Rp. 306.400.273 } \\
\text { IRR }=48 \% \\
\text { B/C Ratio }= \\
2,18\end{array}$ \\
\hline
\end{tabular}

Sumber :Data Primer Diolah 2018

Data dari hasil penelitian Tabel 11 menunjukan bahwa bagaimana kondisi kinjera mesin penggilingan gabah berdasarkan dengan analisis finansial Net Present Value (NPV), Internal Rate of Return (IRR) dan Benefit Cost Ratio (BCR) dimana telah didapatkan hasil analisi NPV pada PGK yaitu Rp. -15.890.115, PGM yaitu dengan hasil Rp. 190.596.835 dan PGB dengan hasil Rp. 306.400.273 dimana nilai pada penggilingan gabah kapasitas besar dan menengah menunjukkan bahwa investasi yang dihasilkan telah memperoleh keuntungan bersih sedangkan pada penggilingan gabah kapasitas kecil menunjukkan investasi yang dijalankan tidak mengalami keuntungan bersih namun mengalami kerugian.

Berdasarkan analisis Internal Rate of Return (IRR) pada PGK yaitu 0,6\%, PGM 24\% dan PGB 48\%, artinya usaha penggilingan gabah kapasitas besar dan menengah ini dapat mengembalikan modal dengan tingkat pinjaman yang dihasilkan berdasarkan dari tingkat suku bunga MARR 20\% sedangkan usaha penggilingan gabah kapasitas kecil tidak mampu untuk mengembalikan modal dengan tingkat pinjaman yang dihasilkan berdasarkan dari tingkat suku bunga MARR 20\%

Berdasarkan analisis Benefit Cost Ratio (BCR) telah didapatkan hasil sampling rata-rata dimana PGK 1,0, PGM 1,75 dan PGB 2,18 dimana usaha penggilingan gabah kapasitas besar dan menengah ini memiliki kegiatan investasi yang bisa dikatakan layak untuk dilanjutkan, sedangkan usaha penggilingan kapasitas kecil memiliki kegiatan investasi yang bisa dikatakan tidak layak untuk dilanjutkan. Setelah kapasitas besar dan menengah dikatakan layak dan kapasitas kecil dikatakan tidak layak, tetapi dari hasil-hasil analisis tersebut yang hanya layak adalah PGB karena nilai yang dihasilkan lebih besar dari PGK dan PGM.

\section{KESIMPULAN DAN SARAN}

\section{Kesimpulan}

Berdasarkan pada tabel Analisis kinerja operasional produktivitas didapatkan kontribusi terhadap kinerja pada PGK yaitu 21,1\%, PGM 32.3\% dan PGB $47,5 \%$. Sehingga dalam penggilingan gabah yang ada di Kecamatan Penebel untuk PGB mempunyai kontribusi terhadap kinerja operasional yang paling besar. Setelah kapasitas besar dan menengah dikatakan layak dan kapasitas kecil dikatakan tidak layak, tetapi dari hasil-hasil analisis tersebut yang hanya layak adalah PGB karena nilai yang dihasilkan lebih besar dari PGK dan PGM.

Perhitungan analisis kelayakan usaha atau kelayakan finansial usaha pertanian penggilingan gabah berkelanjutan dalam setiap kapasitasnya berdasarkan hasil sampling rata-rata di Kecamatan Penebel Kabupaten Tabanan pada tabel kondisi kinerja mesin penggilingan gabah dalam Intensitas Operasi yang dikerjakan dimana pelaku usaha penggilingan gabah besar dan menengah ini memiliki kegiatan investasi yang bisa dikatakan layak untuk dilanjutkan sedangkan kapasitas kecil memiliki kegiatan investasi yang dikatakan tidak layak untuk dilanjutkan, telah didapatlan hasil yaitu Analisis Net Present Value dari penggilingan gabah kapasitas besar sebesar Rp. 306.400.273, penggilingan gabah kapasitas menengah sebesar Rp. 190.596.835 dan penggilingan gabah dengan kapasitas kecil sebesar Rp. -15.890.115. Analisis Internal Rate of Return penggilingan gabah kapasitas besar sebesar 48\%, penggilingan gabah kapasitas menengah sebesar $24 \%$ dan penggilingan gabah kapasitas kecil sebesar 0,6\%. Analisis Benefit Cost Ratio 2,18 didapatkan dari penggilingan gabah kapasitas besar, 1,75 didapatkan dari penggilingan gabah kapasitas menengah dan 1,0 didapatkan dari penggilingan gabah kapasitas kecil. 


\section{Saran}

Saran yang dapat diberikan melalui penelitian ini adalah hasil analisis kelayakan usaha atau finansial yang menunjukkan usaha penggilingan gabah kapasitas besar dan menengah di Kecamatan Penebel ini sangat layak untuk dilanjutkan namun untuk penggilingan gabah kapasitas kecil di Kecamatan Penebel Kabupaten Tabahan ini malah dikatakan tidak layak untuk dilanjutkan maka dari itu sebaiknya usaha Penggilingan dengan kapasitas kecil perlu untuk lebih dikembangkan dan ditingkatkan kembali.

\section{Daftar pustaka}

Analisi biaya penggilingan padi oleh kelompok VIII anggota https://www.academia.edu/11400338.

Diakses pada 7 Agustus 201714.00 wita.

Analisis_model_pengolahan_padi_jep_april_2007.p df.http://mekanisasi.litbang.pertanian.go.id/i nd/phocadownload/JEP/. Diakses pada 7 Agustus 2017.pkl 13.00 wita

Analisis Indeks dan status keberlanjutan sistem ketersediaan beras di beberapa wilayah Indonesia.

http://pustaka.mb.ipb.ac.id/files/2010/07/.

Diakses tanggal : 5 Agustus 2017 pkl.14.00 wita.

Badan Ketahanan Pangan. 2008. Diversifikasi Pangan. Depatemen Pertanian. Jakarta. Budiyanto S dan Sitanggang AB, 2011. Produktivitas dan Penggilingan Padi Terkait dengan Pengendalian Faktor Mutu Berasnya. Jurnal Pangan . Vol.20 No.2:141-15

Badan Pusat Statistik Provinsi Bali. 2015. Bali dalam Angka 2015. www.bali.bps.go.id. Diakses pada 6 Agustus 2017 pkl.10.12 wita.

BP3K Penebel. 2016. Programa Penyuluhan Pertanian Perikanan dan Kehutanan Kecamatan Penebel. BP3K Penebel, Tabanan.

Bulkiya, C. M. 2013. Kajian Mutu Beras pada Berbagai Kadar Air Gabah Kering Giling (GKG) Menggunakan Mesin Penggiling Padi Keliling. Skripsi S1. Tidak dipublikasikan. Program Studi Teknik Pertanian Fakultas Pertanian Universitas Syiah Kuala Darussalam, Aceh

Departemen Pertanian. 2005. Prospek dan Arah Pengembangan Agribisnis Padi. Jakarta.

Dale, V. H., and S. C. Beyeler. 2001. Challenges in The Development and Use of Ecological Indicators. Ecological Indicators 1: 3 - 10.

FS Rencana Kelayakan Pembangunan Unit Penggolahan Beras Modern Rice Milling Unit (RMU) Di Kabupaten Tabanan.
Husein Umar. 2000. "Manajemen Penelitian". Gramedia Pustaka Umum: Jakarta

Karakter fisik gabah. Bbpadi.litbang.pertanian.go.id/2007/10berita/info teknologi/138. Diakses pada 7 Agustus 2017 pkl 11.10 wita.

Malhotra, N. K. 2006. Riset Pemasaran : Pendekatan Terapan. PT Indeks Gramedia. Jakarta.

Nurmalina, R. 2007. Model Ketersediaan Beras Yang Berkelanjutan Untuk Mendukung Ketahanan Pangan Nasional. Disertasi Sekolah Pascasarjana. Institut Pertanian Bogor.

Nurmalina, R. 2008. Analisis Indeks dan status Keberlanjutan sistem Ketersediaan Beras di Beberapa Wilayah Indonesia. Jurnal Agro Ekonomi 29 (1) : 47-79.

Patiwiri, A.W.2006. Teknologi Penggilingan Padi. Gramedia Pustaka Utama, Jakarta.

Pranadji, T. dan W. K. Sejati. 2005. Pengelolaan Serangga dan Pertanian Organik Berkelanjutan di Perdesaan. Forum Penelitian Agro Ekonomi 23(1): 38-47.

Puslitbangtan. 2010. Rencana Strategis Penelitian dan Pengembangan Tanaman Pangan. Renstra 2010-2014. Pusat Penelitian dan Pengembangan Tanaman Pangan. Bogor.

Puslitbangtan. 2011. Inovasi Teknologi Berbasis Ketahanan Pangan Berkelanjutan. Buku 2 Prosiding Seminar Nasional Tanaman Pangan. Pusat Penelitian dan Pengembangan Tanaman Pangan. Bogor.

Rachman, B., I W. Rusastra, Y. Yusdja, A.R. Nurmanaf, Ashari, H. Tarigan, E. Ariningsih, dan Sunarsih. 2009. Kinerja dan Dampak Program Strategis Departemen Pertanian. Laporan Akhir Hasil Penelitian. Pusat Analisis Sosial Ekonomi dan Kebijakan Pertanian. Bogor.

Ridwan Tharis, 2010. Revitalisasi Penggilingan Padi Melalui Inovasi Penyososhan Mendukung Swasembada Beras dan Persaingan Global. Jurnal Pengembangan Inovasi Pertanian 3(3); 171-183

Saad, M.B. 1999. Food Security for The Food Insecure, New Challenges and Renewed Commitment. Centre for Development Studies, University College Dublin, Ireland

Sabiham, S .2008. Manajemen Sumberdaya Lahan dan Usaha Pertanian Berkelanjutan, dalam Arsyad,S dan E. Rustiadi (Ed), Crestpent Press dan Yayasan Obor Indonesia .p.3-16

Suryana, A. dan R. Nurmalina. 1988. Pemuda Pedesaan di Sektor Pertanian. Forum Statistik Media Analisis dan Bahasan Statistik Desember 1988:10 - 18 
Sanim. 2006. Pembangunan Pertanian Berkelanjutan dalam Revitalisasi Pertanian dan Dialog Peradaban. Penerbit Buku Kompas. Jakarta.

Setyono, A. 2009. Perbaikan Teknologi Pascapanen dalam Upaya Menekan Kehilangan Hasil Padi. Orasi Pengukuran Profesor Riset, 25 November 2009. Badan Litbang Pertanian. Jakarta.
Standar mutu gabah dan beras giling \& catid 66: padi \& Item id=59 http://kaltim.litbang.pertanian.go.id/ind/inde x.php?option=com_content $\&$ view $=$ article $\& \mathrm{i}$ $\mathrm{d}=715$. Diakses pada tanggal 2 Oktober 2017 pkl 08.52 wita.

Tingkatkan Persyaratan Kualitas Gabah Petani Bulog.co.id/2008/37/500/ 10/2/2008/ BULOG. Diakses tanggal: 7 Agustus 2017 pkl 10.11 wita 